\title{
Editorial: the two sides of innovation
}

\author{
Guido Buenstorf • Uwe Cantner • Horst Hanusch • \\ Hans-Walter Lorenz • Fritz Rahmeyer
}

Published online: 22 June 2012

(c) Springer-Verlag 2012

Schumpeter's notion of creative destruction is certainly one of the most-cited expressions ever coined by an economist:

"The opening up of new markets, foreign or domestic, and the organizational development from the craft shop and factory to such concerns as U.S. Steel illustrate the same process of industrial mutation [...] that incessantly revolutionizes the economic structure from within, incessantly destroying the old one, incessantly creating a new one. This process of Creative Destruction is the essential fact about capitalism. It is what capitalism consists in and what every capitalist concern has got to live in." Schumpeter (1994, [1942], 82-83).

For Schumpeter, there was no doubt that innovation-coming from within-has a destructive side. Where there are pioneering entrepreneurs, there will also be laggards, "mere managers" (in Schumpeter's terms) who cannot keep up with the pace of change brought about by new combinations in products, processes and organizations. Product innovations may lead to the emergence of entirely new industries - and at the same time trigger the demise of existing ones the products of which are replaced by the innovation. Schumpeter also realized that the structural changes thus brought about could alter the prospects of industries, entire regions and even countries. Actually,

\footnotetext{
G. Buenstorf

University of Kassel, Kassel, Germany

U. Cantner $(\bowtie) \cdot$ H.-W. Lorenz

Friedrich Schiller University Jena, Jena, Germany

e-mail: uwe.cantner@uni-jena.de

H. Hanusch · F. Rahmeyer

University of Augsburg, Augsburg, Germany
} 
he did not speak of "destructive creation" but of "creative destruction"creativity is the qualifying attribute he assigned to an innovative process, while destruction is at its core.

All this is, of course, well-known to evolutionary economists, and much of it has informed key contributions to evolutionary economics. Most of us will agree that capitalism is a restless process (Metcalfe 2008) and that equilibria in markets should be understood as (at most) short-living times of temporary stability during phases of rapid structural change. At the same time, it seems fair to argue that evolutionary economics has been somewhat onesided in its treatment of innovation, with the destructive part of the innovative creation process having received relatively little attention. Adverse effects of innovation are rarely discussed, perhaps due to the underdeveloped nature of evolutionary welfare economics. Entrepreneurship and new firm formation are much more prominent topics in evolutionary economics than is the demise of companies. The work on industry life cycles has focused on explaining the shakeout in the number of firms during the growth phase of an industry, while the later demise of obsolete industries has mostly been eclipsed. Related work has looked at the fate of diversifiers into new industries, while little is known about the post-exit activities of firms withdrawing from a specific market. Many other examples could be provided for the tendency to disregard the destructive side of innovation in the thrust of research in evolutionary economics.

This special issue offers a collection of papers devoted to innovation and its consequences. These papers were presented and discussed at two workshops in Augsburg 2008 and in Jena 2009. The workshops were organized by the section "Evolutionary Economics" of the German Economic Association (Verein für Socialpolitik). The common theme of both workshops was "The Two Sides of Innovation-Creation and Destruction" with a focus on the relationship between innovation and structural change in general and the two sides of that coin-creation on the one hand and destruction on the other. A first group of papers included in this special issue looks at innovation and its effects on economic performance, addressing issues of motives, behavioral rules under uncertainty, actor properties, and technology characteristics. A second group of papers concentrates on potential consequences of innovative activities, in particular, structural change, the "innovation-mediated" effect of skill-oriented policies on regional performance, the destructive effects of innovation activities, and the question whether novelty is always good.

Innovation: conditions to successfully create and economize on them In her paper "Agents of change", Caroline Gerschlager (WU Vienna) suggests that the theory of agents of change, which currently rests mainly on limited cognitive capabilities, be complemented by an analysis of agents' motives. Here, the capacity of actors to change their motives can be seen as another source of innovation in the sense that agents are not only affected by their 
ideas, institutions and technologies (as in the cognitive approach), but also deliberately affect and choose their ideas, institutions and technologies.

Behavioral rules under uncertainty, as encountered in basic science, are the concern of Thomas Grebel (Friedrich Schiller University Jena) in his paper "Network evolution in basic science". Based on an empirical study in cardiology, he discusses specific behavioral rules in the initial phase of starting a research project based on received information or perceived competition, as well as rules relating to cooperation and imitation. Applying these rules in a percolation model, his simulation analyses find that, along with the diffusion of new information, specific leader-follower as well as cooperationnon-cooperation structures emerge.

Looking at inventor networks from an empirical point of view, the development of those networks and the relationship to the degree of generality of the pursued technology are analyzed by Holger Graf (Friedrich Schiller University Jena) in his paper "Inventor networks in emerging key technologies: information technology vs. semiconductors". Technologies that move to the core of the knowledge base-such as semiconductors-are considered to be key technologies allowing for further knowledge-widening activities; hence, associated structures of the inventor network should exhibit a high degree of connectedness. In contrast, other technologies which do not move very much in the knowledge space—such as information technologies—are characterized by knowledge-deepening activities, so that the emerging structure of an inventor network shows lower connectedness.

Looking at the commercialization of inventions, the problem of the transfer of the results in basic science, i.e. academic inventions, into economic usage is addressed in "Not invented here: technology licensing, knowledge transfer and innovation based on public research" by Guido Buenstorf and Matthias Geissler (University of Kassel). Licensing to external actors and licensing to academic spin-offs are alternative channels for successfully commercializing academic inventions. Their effectiveness is analyzed on the basis of data from the Max Planck Society in Germany. The results indicate that academic spinoffs, compared to external licensing, do not have a systematic disadvantage in commercializing inventions. Hence, from a policy perspective, spin-offs should not be considered an inferior solution applicable only when external licensees are not available.

Innovation: induced structural change, coping and evaluation A simulation study looking at innovation activities, the diffusion of innovations and the resulting structural change is presented by Frank Beckenbach, Maria Daskalakis and David Hofmann (University of Kassel) in "Agent-based modelling of novelty creating behavior and sectoral growth effects-Linking the creative and the destructive side of innovation". The multilevel model represents the relationship between agents' novelty-creating activities, on the one hand, and the growth of economic aggregates, on the other. The model reproduces some stylized facts of the knowledge-generating process, such as the persistence of actor heterogeneity, the emergence of innovating agents as a specific 
property of the model, and the inverse cyclical pattern of innovation and imitation.

The economic performance of regions as measured by total factor productivity, the importance of the quality of capital and of skilled labor therein, and the role of labor market policies are discussed in "Labor market integration policies and the convergence of regions: the role of skills and technology diffusion" by Herbert Dawid, Simon Gemkow, Philipp Harting (all University of Bielefeld) and Michael Neugart (Free University of Bozen). The authors contrast alternative labor market integration policies resulting in distinct regional distributions of specific skills. As a consequence, a trade-off between convergence and the level of output is identified. In the case of a closed labor market, a high degree of convergence is combined with a low level of output, whereas a more open labor market implies a higher output level combined with a lower tendency for convergence.

The issue of (creative) destruction is taken up by Lars Feld (Albert Ludwigs University Freiburg \& Walter Eucken Institute), Jan Schnellenbach (Ruprecht Karls University Heidelberg) and Thushyanthan Baskaran (Georg August University Göttingen) in "Creative destruction and fiscal institutions: a longrun case study of three regions". Analyzing the cases of the declining steel and mining industry in three political regions, the authors investigate the distinct regional fiscal constitutions and the associated transfer payments for the obstruction or the encouragement of structural change in the private sector. For a region with fiscal autonomy, the authors find a relatively faster decline of employment in the particular sectors. For non-autonomous regions, transfers do not accelerate structural change, but have a more preserving effect.

In "Is novelty always a good thing? Towards an evolutionary welfare economics" Christian Schubert (Max Planck Institute of Economics, Jena) questions the position that innovation is always something good in the sense of increasing welfare-a position usually_and mostly implicitly-adopted by policy makers trying to foster innovation activities. In discussing this issue, and by critically reflecting on traditional welfare economics, the author develops a concept of welfare in a world of variable and often incoherent preferences. In his new conception, welfare at the individual level is understood as the capacity and motivation to engage in the ongoing learning of instrumentally effective preferences. In this sense, innovation is beneficial if it enlarges a person's freedom to choose among different paths of preference learning. Innovation policy is beneficial if it promotes an individual's ability to learn and to explore new preferences.

Taken together, the papers in this Special Issue depict a necessarily selective but hopefully also representative perspective on the "perennial gales of creative destruction" as envisaged by Schumpeter. Certainly, research along these lines has still been devoted to creativity issues of innovation processes and our insights have continuously advanced in this place. A more complete picture, however, should take the destructive aspects of an innovation-driven 
development on board and should emphasize the intertwinement with creative aspects of innovative activities. Since the literature concentrating on these topics is still rather sparse and in its infancy, we hope that the papers collected in this Special Issue serve as a trigger for further research along these lines.

Mai 2012, Augsburg, Jena and Kassel

Guido Buenstorf, Uwe Cantner, Horst Hanusch, Hans-Walter Lorenz, Fritz Rahmeyer

\section{References}

Metcalfe S (2008) Restless capitalism - the evolutionary nature of competition. Princeton University Press, Princeton/NJ

Schumpeter JA (1994) [1942] Capitalism, socialism and democracy. Routledge, London 